\title{
TURFEIRAS DA SERRA DO ESPINHAÇO MERIDIONAL - MG. I - CARACTERIZAÇÃO E CLASSIFICAÇÃ̃O ${ }^{(1)}$
}

\author{
Alexandre Christófaro Silva ${ }^{(2)}$, Ingrid Horák ${ }^{(3)}$, Antonio Martinez \\ Cortizas $^{(4)}$, PabloVidal-Torrado ${ }^{(5)}$, Jose Rodrigues Racedo(4), Paulo \\ Henrique Grazziotti (2), Enilson de Barros Silva ${ }^{(2)} \&$ Celmo Aparecido \\ Ferreira $^{(6)}$
}

\begin{abstract}
RESUMO
As turfeiras são ambientes especiais para estudos relacionados com a dinâmica da matéria orgânica, evolução das paisagens, mudanças climáticas e ciclos de poluição atmosférica locais, regionais e globais. Elas contribuem para o sequestro global de carbono, funcionam como reservatórios de água e constituem o ambiente de uma biodiversidade endêmica. A Serra do Espinhaço Meridional (SdEM), "Reserva da Biosfera Terrestre", apresenta uma área significativa formada por diferentes tipos de turfeira, que foram descritas em três perfis, situados a $1.250 \mathrm{~m}$ (P1), $1.800 \mathrm{~m}(\mathrm{P} 2)$ e $1.350 \mathrm{~m}$ (P4) de altitude e classificados respectivamente como Organossolo Háplico Sáprico térrico (P1), Organossolo Háplico Fíbrico típico (P2) e Organossolo Háplico Hêmico típico (P4), de acordo com o Sistema Brasileiro de Classificação de Solos. Os três perfis foram caracterizados morfologicamente e, nas amostras coletadas, foram realizadas análises químicas, físicas e microbiológicas. Verificou-se que a localização, a altitude e a drenagem influenciaram os atributos morfológicos, físicos, químicos e microbiológicos das turfeiras da SdEM. O estádio de decomposição da matéria orgânica é mais avançado com a melhoria da drenagem nas turfeiras. $O$ teor de metais pesados está relacionado com o teor e a composição granulométrica da fração mineral e com a localização das turfeiras. O perfil $\mathrm{P} 1$ apresentou os mais elevados teores médios de Ti, Zr e Pb; em P2 foram detectados os teores médios mais elevados de Mn, Zn e Cu;
\end{abstract}

\footnotetext{
(1) Recebido para publicação em novembro de 2008 e aprovado em maio de 2009.

${ }^{(2)}$ Professor da Faculdade de Ciências Agrárias, Universidade Federal dos Vales do Jequitinhonha e Mucuri - UFVJM. Caixa Posta 38, Rod. MGT 367, Km 583, CEP 39100-000 Diamantina (MG). E-mail: alexandre.christo@ufvjm.edu.br

(3) Bolsista de Iniciação Científica da FAPEMIG, UFVJM. E-mail: E-mail: ihorak@esalq.usp.br

(4) Departamento de Edafoloxia, Facultad de Bioloxia, Universidad de Santiago de Compostela. CP 15706, Santiago de Compostela, Espanha. E-mail: edanton@usc.es

${ }^{(5)}$ Professor do Departamento de Solos e Nutrição de Plantas, Escola Superior de Agricultura "Luiz de Queiroz" - ESALQ/USP. Caixa Postal 9, Av. Pádua Dias 11, CEP 13418-900 Piracicaba (SP). E-mail: pablo@carpa.ciagri.usp.br

${ }^{(6)}$ Discente do Programa de Mestrado em Produção Vegetal, UFVJM. E-mail: agrocel_1@yahoo.com.br
} 


\begin{abstract}
e o teor médio de Fe é mais elevado em P4. A intensidade da atividade microbiológica das turfeiras $\mathrm{P} 2$ e $\mathrm{P} 4$ relacionou-se com sua drenagem e com o teor de metais pesados de suas camadas.
\end{abstract}

Termos de Indexação: Organossolos, matéria orgânica do solo, escala de von Post, metais pesados.

\title{
SUMMARY: PEAT BOGS OF THE SERRA DO ESPINHAÇO MERIDIONAL - MINAS GERAIS, BRAZIL. I - CHARACTERIZATION AND CLASSIFICATION
}

\begin{abstract}
Peat bogs are a special environment for studies related with the dynamics of organic matter, landscape evolution and climatic changes and with local, regional and global cycles of atmospheric pollution. Peat bogs contribute to the global C sequestration, act as water reservoirs and are the habitat of an endemic biodiversity. The Serra do Espinhaço Meridional (Minas Gerais State, Brazil) - SdEM-a terrestrial biosphere reservation area, contains a considerably large area with different types of peat bogs, which were described in three profiles at 1,250, 1,800 and 1,350 $\mathrm{m}$ above sea level and classified, respectively, as Organosol Haplic sapric terric (P1), Organosol Haplic fibric typical (P2) and Organosol Haplic Hemic typical (P4), in agreement with the Brazilian System of Soil Classification. The three profiles were characterized morphologically and the samples were chemically, physically and microbiologically analyzed. It was found that the location, altitude and drainage influenced the morphologic, physical, chemical, and biological properties of the peat bogs in SdEM. The decomposition state of organic matter is more advanced when the drainage in the peat bogs is better. The amount of heavy metals is related with the quantity and granulometric composition of the mineral fraction and location of the peat bogs. The highest mean levels of $\mathrm{Ti}, \mathrm{Zr}, \mathrm{Pb}$ were detected in profile P1, highest mean levels of $\mathrm{Mn}, \mathrm{Zn}$ and $\mathrm{Cu}$ in P2, and the highest mean Fe content in P4. The intensity of microbiological activity in the peat bogs $P 2$ and $P 4$ was related with the drainage and heavy-metal content of its layers.
\end{abstract}

Index terms: Organosols, soil organic matter, von Post scale, heavy metals.

\section{INTRODUÇÃO}

Turfeiras são definidas por Pontevedra-Pombal \& Martinez-Cortizas (2004) como um ecossistema úmido, composto principalmente por plantas higrófilas que, ao crescerem e sucederem-se no tempo e no espaço, acumulam grande quantidade de matéria vegetal morta. Moore (1989) considera as turfeiras um sistema de elevada energia, que concentra a energia solar dispersa entre os organismos do solo em forma de turfa, originando um desequilíbrio, pelo fato de a relação acúmulo/decomposição-mineralização da matéria orgânica ser bem superior à unidade.

As turfeiras são habitats de escassa representação em nível mundial, ocupando cerca de 420 milhões de hectares, dos quais cerca de dois terços se localizam na Rússia e Canadá. Considerando uma espessura média de $2 \mathrm{~m}$, acumulam 455 bilhões de toneladas de carbono orgânico (Gorham, 1991). Nos ambientes tropicais as turfeiras são menos comuns. Ocupam pouco mais de $0,1 \%$ do território brasileiro (Pereira et al., 2005; Valladares et al., 2008), ocorrendo em elevações quartzíticas (Dias et al., 2003) e em planícies fluviais e mangues (Embrapa, 1978; Lani, 1998; PradaGamero et al., 2004). Valladares (2003) encontrou 129 perfis de Organossolos descritos em levantamentos de solos de diversas regiões do Brasil, dos quais $25 \% \mathrm{em}$ elevações acima de $1.200 \mathrm{~m}$ de altitude.

Shotyk et al. (1997) caracterizam turfeiras como arquivos ambientais e cronológicos da evolução das paisagens, de mudanças climáticas e da deposição atmosférica de metais pesados em escala regional ou mesmo global. Martinez-Cortizas et al. $(1997,1999)$ encontraram picos de acumulação de $\mathrm{Hg}$ e de $\mathrm{Pb}$ em perfis de turfeiras da Espanha durante os últimos 4.000 anos e os correlacionaram, respectivamente, com a atividade humana e paleoclimas e com marcos históricos e pré-históricos da exploração mineral na Península Ibérica. Shotyk et al. (1998) também encontraram picos de acúmulo de $\mathrm{Pb}$ em perfis de turfeiras em montanhas da Suíça durante os últimos 12.400 anos e os correlacionaram com atividades de mineração e metalurgia, vulcanismo e mudanças climáticas. O estudo de turfeiras do sul da Polônia 
permitiu a Jedrysek et al. (2003) evidenciar fases de maior ou menor poluição atmosférica e mudanças climáticas nos últimos 1.100 anos. Trabalho de Espi et al. (1997) em turfeiras de elevada altitude, na Bolívia, mostrou grande variação dos teores de $\mathrm{Cu}$, $\mathrm{Zn}, \mathrm{Hg}$ e $\mathrm{Pb}$ em profundidade, nos últimos 300 anos.

As turfeiras de ambiente tropical de elevadas altitudes e clima atual ameno, como as da Serra do Espinhaço Meridional (SdEM), possuem idades superiores a 30.000 anos (Augustin, 1994; Silva, 2004d). São, portanto, mais antigas do que as turfeiras de ambientes polares ou temperados, as quais possuem idades de no máximo 15.000 anos (Martinez-Cortizas et al., 1999, 1997; Shotyk et al., 1998; Jedrysek et al., 2003). Como essas turfeiras são pouco estudadas, ainda é pequeno o número de informações a respeito de seu potencial para estudos de mudanças climáticas, evolução das paisagens, endemismos bióticos e da cronologia de deposições atmosféricas de metais pesados.

Os solos das turfeiras são classificados como Organossolos Tiomórficos, Fólicos ou Háplicos de acordo com o Sistema Brasileiro de Classificação de Solos (Embrapa, 2006); como Histosols, na Taxonomia Americana de Solos (USDA, 1999); e como Histosols, na Classificação de Solos da FAO - UNESCO (1990).

Além de contribuírem para o sequestro global de carbono, as propriedades e os componentes desses pedoambientes lhes permitem funcionar como autênticos reservatórios de água, intervindo no controler hidrológico (Lévesque \& Dínel, 1982). Ao controlarem a descarga hídrica oriunda de chuvas de elevada intensidade, minimizam a erosão nas áreas adjacentes de menor altitude (Gorham, 1991). Em face de sua influência na composição química das águas que a permeiam, as turfeiras também protegem os sistemas de água doce, ao prevenirem a eutrofização (Maltby \& Dugan, 1994).

A Comunidade Econômica Europeia (CEE) considerou, por meio de Instrução Diretiva de 1992, as turfeiras como ambientes naturais de interesse comunitário prioritário especial para conservação (DOCE, 1992). A Espanha protegeu integralmente as turfeiras em 1995 por meio de Decreto Real (Pontevedra-Pombal \& Martinez-Cortizas, 2004). No Brasil, a Serra do Espinhaço Meridional foi reconhecida pela UNESCO em 2005 como "Reserva da Biosfera Terrestre" (Silva et al., 2005), o que ressalta seu valor ambiental e a importância de preservação de seus ecossistemas turfosos. Em trabalhos de reconhecimento de solos em unidades de conservação da SdEM, Silva (2004a,b,c, 2005b) mapeou Organossolos em diferentes altitudes e condições de drenagem.

O presente trabalho teve como objetivos caracterizar os atributos morfológicos, físicos, microbiológicos e químicos e classificar as turfeiras da SdEM de acordo com o Sistema Brasileiro de
Classificação de Solos, bem como testar a hipótese de que a altitude e as condições de drenagem influem na classificação e caracterização das turfeiras.

\section{MATERIAL E MÉTODOS}

\section{Caracterização do ambiente}

$\mathrm{Na}$ Serra do Espinhaço Meridional, as superfícies de aplainamento escalonadas estão separadas por áreas com alto grau de dissecação, onde o relevo é montanhoso e escarpado e são muito frequentes os afloramentos de rochas metareníticas do Supergrupo Espinhaço, também formado por filitos e rochas básicas, em menor proporção (Silva et al., 2005). Os solos predominantes são Neossolos Litólicos Psamíticos, Neossolos Quartzarênicos Hidromórficos e Neossolos Quartzarênicos Órticos (Silva, 2004a,b,c, 2005b). Apresentam substratos de tipologias do bioma Cerrado, como o campo rupestre e o campo Cerrado, que abrigam espécies endêmicas das famílias Orchidaceae, Bromeliaceae, Xyridaceae e Velloziaceae, bem como espécies endêmicas da fauna (Silva et al., 2005). Diversas depressões das superfícies de aplainamento, as cabeceiras de drenagem, estão preenchidas por turfeiras e constituem nascentes de inúmeros cursos de água de coloração escura.

O clima é, de acordo com a classificação de Koppen, Cwb, ou seja, mesotérmico. A temperatura média anual é de $18,7^{\circ} \mathrm{C}$, com invernos frios e secos e verões brandos e úmidos, e a precipitação média anual é de $1.500 \mathrm{~mm}$ (Silva et al., 2005).

\section{Localização, descrição e amostragem}

A SdEM possui cerca de 4.000 .000 ha. Os solos de cinco unidades de conservação da SdEM foram mapeados na escala de 1:25.000, abrangendo 112.233 ha, dos quais 12.814 ha correspondem a unidades de mapeamento onde Organossolos ocorrem associados a outros solos (Silva, 2004a,b,c, 2005). Após a identificação e descrição de 72 locais com ocorrência de Organossolos, três perfis de turfeiras, representativos de todos os Organossolos da SdEM, foram descritos morfologicamente em detalhes e amostrados: P1 Fazenda São Miguel - Parque Estadual do Biribiri Diamantina; P2 - Parque Estadual do Pico do Itambé - Santo Antônio do Itambé; e P4 - Área de Proteção Ambiental Pau-de-Fruta-Diamantina (Figura 1). No quadro 1 são apresentadas as coordenadas e a altitude dos perfis estudados.

A turfeira P1 foi descrita e amostrada no topo de uma superfície de aplainamento, na cabeceira do Córrego São Miguel (Figura 1). Apresenta camadas ricas em matéria orgânica alternadas com camadas de pequena espessura formadas praticamente por areia. A exploração de diamante e ouro é realizada no local, segundo depoimento do sr. Geraldo Miranda, proprietário da Fazenda São Miguel - pelo menos há 

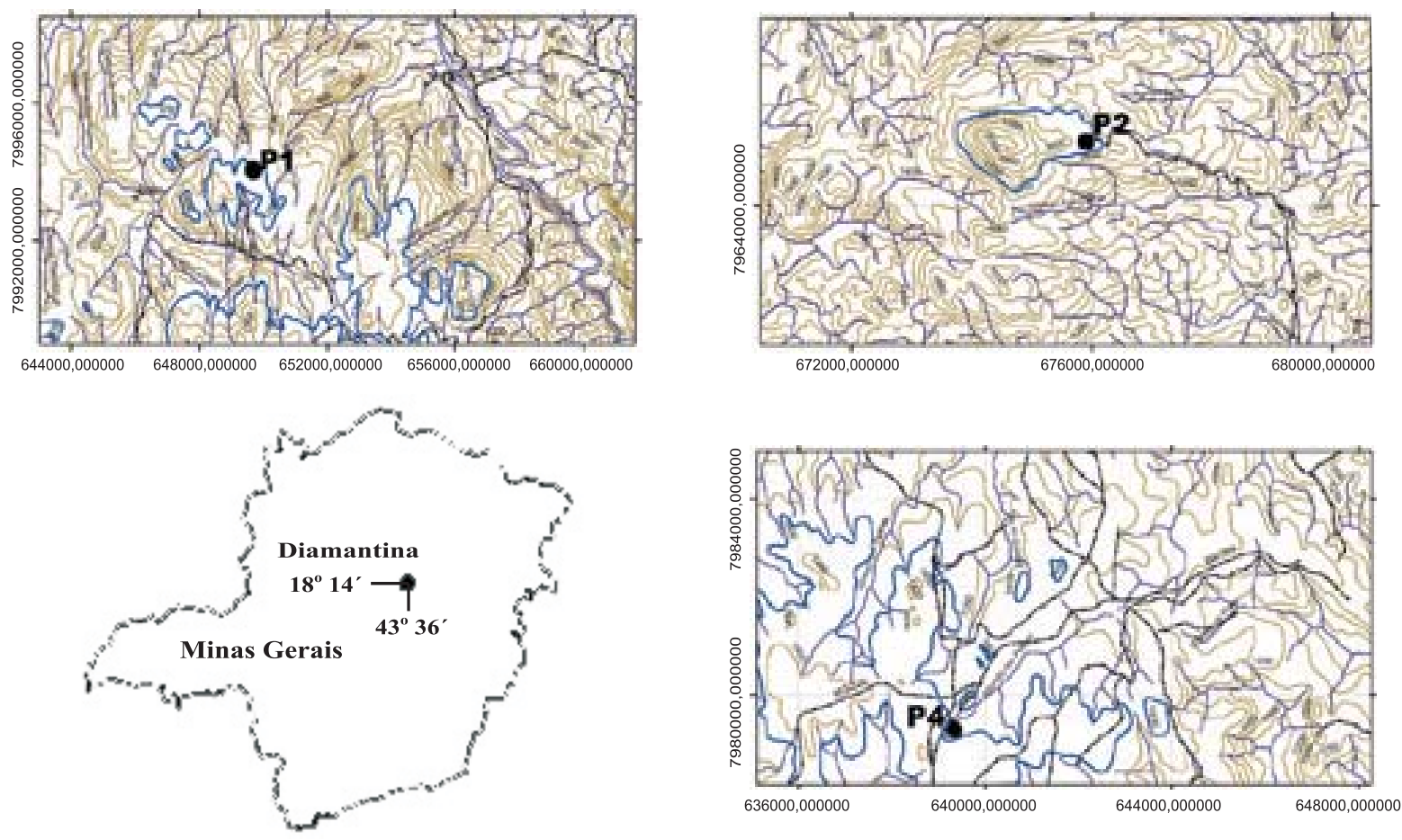

Figura 1. Localização das áreas de estudo. O mapa onde os perfis P1 e P4 estão localizados corresponde à carta topográfica Diamantina - Folha SE-23-Z-B-I e o mapa onde o perfil P2 está localizado corresponde à carta topográfica Rio Vermelho - Folha SE-23-Z-A-III, ambas na escala original de 1:100.000, digitalizadas utilizando o software Arc View 9.0.

Quadro 1. Locais de descrição e amostragem das turfeiras da Serra do Espinhaço Meridional

\begin{tabular}{|c|c|c|c|}
\hline \multirow{2}{*}{ Perfil } & \multicolumn{2}{|c|}{ Coordenadas geográficas } & \multirow{2}{*}{ Altitude } \\
\hline & UTM & Graus & \\
\hline & & & $\mathrm{m}$ \\
\hline $\mathrm{P} 1$ & $\begin{array}{l}7994039 \mathrm{~N} \\
649691 \mathrm{E}\end{array}$ & $\begin{array}{l}18^{\circ} 08^{\prime} 6,9^{\prime \prime} \mathrm{S} \\
43^{\circ} 35^{\prime} 6,2^{\prime \prime} \text { WGR }\end{array}$ & 1.250 \\
\hline $\mathrm{P} 2$ & $\begin{array}{l}7965062 \mathrm{~N} \\
675923 \mathrm{E}\end{array}$ & $\begin{array}{l}18^{\circ} 25^{\prime} 22^{\prime \prime} \mathrm{S} \\
43^{\circ} 22^{\prime} 30^{\prime \prime} \text { WGR }\end{array}$ & 1.800 \\
\hline $\mathrm{P} 4$ & $\begin{array}{l}7979340 \mathrm{~N} \\
639167 \mathrm{E}\end{array}$ & $\begin{array}{l}18^{\circ} 16^{\prime} 15^{\prime \prime} \mathrm{S} \\
43^{\circ} 41^{\prime} 0,5^{\prime \prime} \text { WGR }\end{array}$ & 1.350 \\
\hline
\end{tabular}

dois séculos. Ela foi responsável pelo rebaixamento da rede de drenagem, e o leito do Córrego São Miguel situa-se nos dias atuais a mais de 3,5 m do nível da superfície de aplainamento (Figura 2). O rebaixamento da rede de drenagem, verificado pela melhora da drenagem interna determinada de acordo com Santos et al. (2005) e Embrapa (2006), expôs a turfeira no talvegue do Córrego São Miguel. Nesta turfeira foram coletadas amostras nas seguintes profundidades, de acordo com a morfologia das camadas: 6-66; 80-116; 118-122; 124-132; 140-150; 156-166; e 170-174 cm.
A turfeira P2 (Figura 1) situa-se no topo de um pequeno testemunho de uma superfície de aplainamento a $1.800 \mathrm{~m}$ de altitude, que corresponde a uma das nascentes do Córrego Água Branca e é muito mal drenada (Santos et al., 2005; Embrapa, 2006). Apresenta $50 \mathrm{~cm}$ de espessura e, como seu perfil é muito homogêneo, foi amostrada a cada $10 \mathrm{~cm}$ de profundidade.

A turfeira P4 (Figura 1) foi descrita no topo de uma superfície de aplainamento a $1.350 \mathrm{~m}$ de altitude; corresponde à área onde nasce o Córrego das Pedras, manancial que abastece a cidade de Diamantina-MG, e é muito mal drenada (Santos et al., 2005; Embrapa, 2006). Apresenta $90 \mathrm{~cm}$ de espessura; como seu perfil é muito homogêneo, foi amostrada a cada $10 \mathrm{~cm}$ de profundidade.

Em todos os perfis também foram coletadas amostras a cada $2 \mathrm{~cm}$, para determinação dos teores totais de $\mathrm{Cu}, \mathrm{Zn}, \mathrm{Mn}, \mathrm{Fe}, \mathrm{Pb}, \mathrm{Ti}, \mathrm{Zr}$ e C.

Para realização das análises em laboratório, as amostras foram secas ao ar, destorroadas e passadas em peneiras de malha de 2,0 $\mathrm{mm}$, obtendo-se assim a terra fina seca ao ar (TFSA).

\section{Determinações analíticas}

No campo, foi realizado o teste para determinação do estádio de decomposição das camadas das turfeiras, 


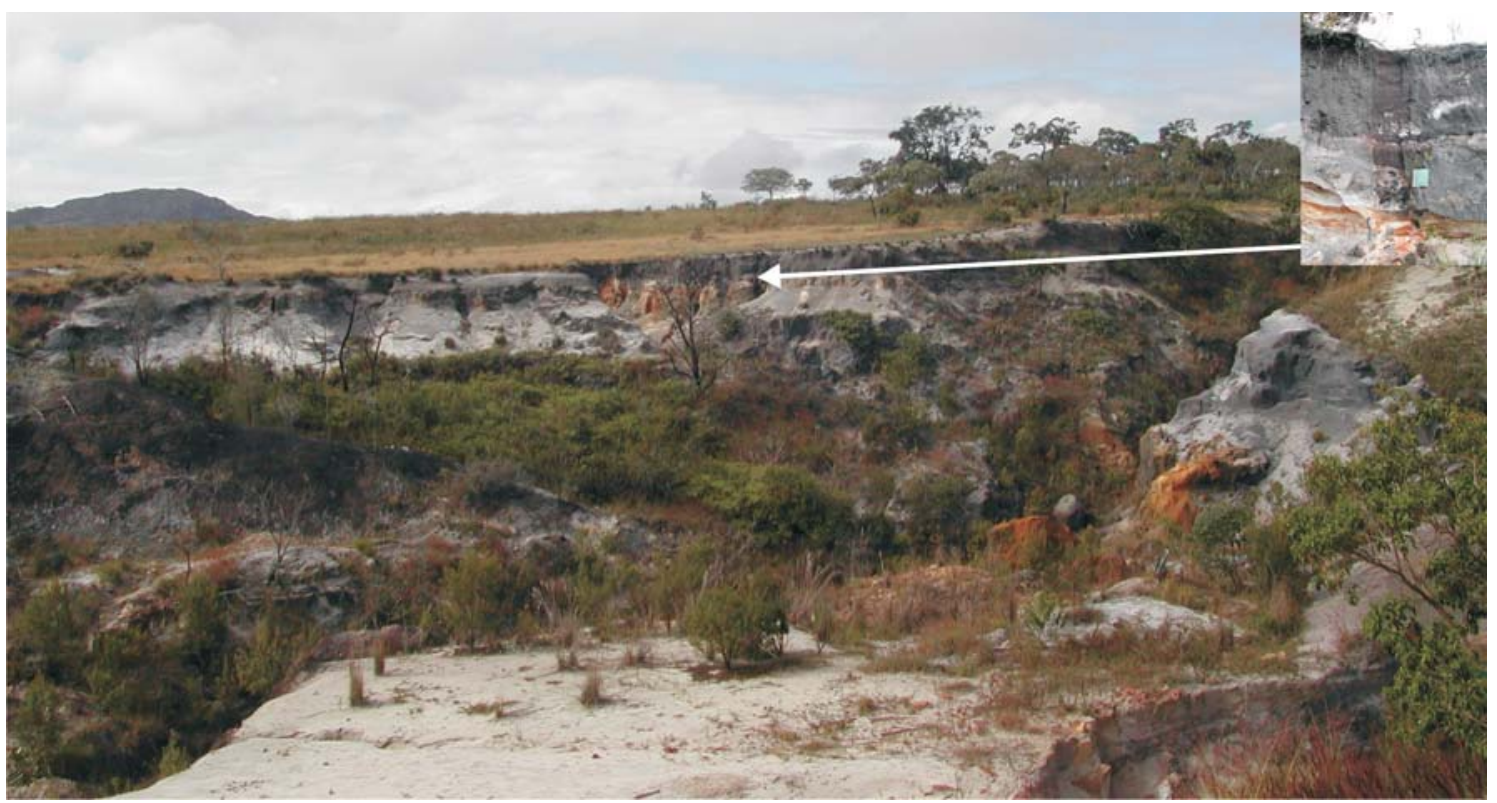

Figura 2. Topo de superficie de aplainamento onde se situa P1 (a); perfil da turfeira P1 (b). Parque Estadual

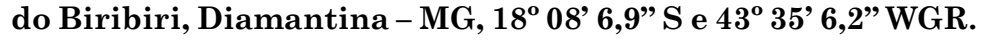

utilizando a escala de decomposição de von Post (Stanek \& Silc, 1977; Embrapa, 2006). O método consiste na compressão de uma amostra de turfeira entre os dedos para avaliação da presença e da coloração da água obtida dessa maneira.

Para quantificação dos teores de carbono orgânico (Corg), a TFSA foi moída em gral de porcelana e tamisada na peneira de $0,053 \mathrm{~mm}$. Posteriormente, procedeu-se à oxidação via úmida com $\mathrm{K} 2 \mathrm{Cr} 2 \mathrm{O} 7$ $0,4 \mathrm{~mol} \mathrm{~L}^{-1}$ e titulação pelo $\mathrm{Fe}(\mathrm{NH} 4) 2(\mathrm{SO} 4) 2.6 \mathrm{H} 2 \mathrm{O}$ $0,1 \mathrm{~mol} \mathrm{~L}^{-1}$ com difenilamina como indicador (Embrapa, 2006).

As análises químicas de rotina [fósforo disponível, elementos do complexo sortivo $\left(\mathrm{Ca}^{2+} ; \mathrm{Mg}^{2+} ; \mathrm{Al}^{3+}\right.$ extração com $\mathrm{KCl} 1 \mathrm{~mol} \mathrm{~L}^{-1} ; \mathrm{K}^{+}$, extração com Mehlich 1) e acidez total] foram feitas na TFSA, de acordo com Embrapa (1997), com exceção do H + Al, extraído com acetato de cálcio $0,5 \mathrm{~mol} \mathrm{~L}^{-1}$ (Silva, 1999). $\mathrm{O} \mathrm{pH}$ em $\mathrm{CaCl}_{2}$, a solubilidade da amostra em pirofosfato de sódio, a densidade do solo (DS), a densidade da matéria orgânica (Dmo), o resíduo mínimo (RM), o material mineral (MM) e a determinação do teor de fibras esfregadas (FE) foram determinados de acordo com o método preconizado pela Embrapa (2006).

Os teores de areia, silte e argila foram determinados pelo método da pipeta (Embrapa, 1997), após a queima total da matéria orgânica das amostras com $\mathrm{H}_{2} \mathrm{O}_{2}$, para obtenção da fração mineral (FM).

A respiração microbiana e a capacidade máxima de retenção de água (CMRA) foram avaliadas pelo método de Isermeyer (1952), citado por Alef \& Nannipieri (1995). Para determinação da CMRA, as amostras foram secas em estufa e pesadas. Posteriormente, foram saturadas com água e drenadas naturalmente até a eliminação do excesso de água e, então, pesadas novamente. A diferença entre a primeira e a última pesagem é a CMRA. O carbono da biomassa microbiana foi determinado pelo método da fumigação-incubação (Jenkinson \& Powlson, 1976), sendo também calculado o quociente metabólico $\mathrm{qCO}_{2}$.

As concentrações de $\mathrm{Cu}, \mathrm{Zn}, \mathrm{Mn}, \mathrm{Fe}, \mathrm{Pb}, \mathrm{Ti}, \mathrm{Zr}$ e Al das amostras coletadas a cada $2 \mathrm{~cm}$ de profundidade foram determinadas em amostras de TFSA moídas no gral de porcelana e tamisadas em peneira com malha de $0,053 \mathrm{~mm}$. A determinação do Corg foi realizada em analisador elementar LECO CHN 1000 (Nelson \& Sommers, 1996), usando como materiais de referência Elemental Micronalysis B2115 e B2152; e LECO 502-092, 502-308 e 502-309. As concentrações de metais foram determinadas por fluorescência de raios X, pela técnica EMMA (Energy Dispersive Miniprobe Multielement Analyser), de acordo com o método preconizado por Cheburkin \& Shotyk (1996), utilizando como materiais de referência NIST: 1515, 1547, 1570a, 1573a, 1575, 1575a, 8412, 8432, 8433, 8436, 8437, 8438; BCR: 60, 62; NIM001; CTA-VTL-2; e CRM-NJV Sphagnum peat.

\section{Análises estatísticas}

Determinou-se o modelo de equação de regressão que melhor explica o comportamento de uma variávelresposta em função de uma variável preditora e estimou-se o coeficiente de correlação de Pearson (r) entre os valores da variável preditora e os valores esperados para a variável-resposta. A significância de $r$ foi estimada pelo teste t de Student a $5 \%(p<0,05)$ e a $1 \%(p<0,01)$. Procedeu-se à análise de variância (classificação hierárquica) para verificar diferenças 
estatisticamente significativas entre os perfis estudados, para todas as variáveis quantitativas. $\mathrm{Na}$ determinação do contraste entre médias utilizou-se o teste de Scheffé a $5 \%(p<0,05)$.

\section{RESULTADOS E DISCUSSÃO}

\section{Atributos morfológicos e físicos}

A cor de todas as amostras úmidas, segundo os padrões da carta de Munsell, no campo, é preta (matizes variados, mas croma igual a 2 ou 2,5 e valor igual a 1). A coloração das amostras obtidas por meio da solubilidade em pirofosfato de sódio variou de preta (10YR 2/1) a bruno-escura (10YR 3/3) em P1, de brunoamarelada (10YR 5/4) a bruno-clara (10YR 6/3) em
P2 e de preta a bruno (10YR 4/3) em P4 (Quadro 2). Quanto mais escura a cor, mais acentuada é a decomposição da matéria orgânica (Valladares, 2003), o que corrobora a classificação de P1, P2 e P4, segundo a escala de von Post (Embrapa, 2006), respectivamente como sáprico, fíbrico e hêmico.

Tanto a densidade do solo (DS) quanto o resíduo mínimo (RM) e o material mineral (MM) estão relacionados ao teor de matéria orgânica (MO) e ao seu grau de decomposição (Conceição et al., 1999). O perfil P1 possui os maiores valores de DS, RM e MM ( $p<0,01$ pelo teste $\mathrm{F}$ e $\mathrm{p}<0,05$ pelo teste de Scheffé - Quadro 2) e apresenta a matéria orgânica em estádio mais avançado de decomposição (sáprico). Também apresenta menor valor de CMRA ( $p<0,01$ pelo teste $\mathrm{F}$ e $\mathrm{p}<0,05$ pelo teste de Scheffé - Quadro 2), em razão dos mais baixos teores de matéria orgânica e dos mais elevados valores da FM, em que predomina a fração areia.

Quadro 2. Cor (Munsel) pelo pirofosfato densidade do solo (DS), densidade da matéria orgânica (Dmo), capacidade máxima de retenção de água (CMRA), resíduo mínimo (RM), material mineral (MM), fibra esfregada (FE) e escala de von Post de decomposição do material orgânico de perfis de turfeiras da Serra do Espinhaço Meridional

\begin{tabular}{|c|c|c|c|c|c|c|c|c|c|}
\hline Perfil & Profundidade & $\begin{array}{c}\text { Cor pelo } \\
\text { pirofosfato }\end{array}$ & $\mathbf{D S}^{(1)}$ & $\operatorname{Dmo}^{(1)}$ & $\mathrm{CMRA}^{(2)}$ & $\mathbf{R M}^{(1)}$ & $\mathbf{M M}^{(1)}$ & $\mathrm{FE}^{(1)}$ & $\begin{array}{l}\text { Estádio de } \\
\text { decomposição do } \\
\text { material orgânico }\end{array}$ \\
\hline \multirow{8}{*}{$\mathrm{P} 1$} & $\mathrm{~cm}$ & & \multicolumn{2}{|c|}{$\mathrm{kg} \mathrm{dm}^{-3}$} & \multicolumn{4}{|c|}{ - dag kg ${ }^{-1}$} & \multirow{10}{*}{$\begin{array}{l}\text { sáprico } \\
\text { sáprico } \\
\text { sáprico } \\
\text { sáprico } \\
\text { hêmico } \\
\text { sáprico } \\
\text { sáprico }\end{array}$} \\
\hline & $6-66$ & 10YR 2/1 & 1,29 & 0,07 & 43 & 82 & 95 & 36 & \\
\hline & $80-116$ & 10 YR $2 / 2$ & 1,34 & 0,06 & 38 & 86 & 96 & 32 & \\
\hline & $118-122$ & $10 \mathrm{YR} 2 / 2$ & 1,38 & 0,05 & 32 & 89 & 96 & 36 & \\
\hline & $124-132$ & $10 Y R 3 / 2$ & 1,31 & 0,05 & 33 & 84 & 96 & 24 & \\
\hline & $140-150$ & 10YR $3 / 3$ & 1,38 & 0,03 & 30 & 90 & 98 & 32 & \\
\hline & $156-166$ & 10YR $2 / 2$ & 1,42 & 0,07 & 36 & 90 & 95 & 24 & \\
\hline & $170-174$ & 10YR 2/1 & 1,35 & 0,06 & 35 & 86 & 95 & 38 & \\
\hline Média & & & $1,35 \mathrm{~A}^{* *}$ & $0,06 \mathrm{~B}^{* *}$ & $35 \mathrm{~B} * *$ & $87 A^{* *}$ & $96 \mathrm{~A}^{* *}$ & $32 \mathrm{~B}^{* *}$ & \\
\hline Desvio-padrão & & & 0,04 & 0,01 & 4,31 & 3,09 & 1,07 & 5,71 & \\
\hline \multirow[t]{5}{*}{$\mathrm{P} 2$} & $0-10$ & 10YR 6/3 & 0,37 & 0,24 & 396 & 8 & 34 & 61 & fíbrico \\
\hline & $10-20$ & $10 Y R 5 / 4$ & 0,41 & 0,31 & 342 & 7 & 25 & 68 & fíbrico \\
\hline & $20-30$ & $10 Y R 5 / 4$ & 0,31 & 0,30 & 271 & 0,5 & 2 & 70 & fíbrico \\
\hline & $30-40$ & $10 Y R 6 / 3$ & 0,28 & 0,27 & 205 & 0,6 & 3 & 53 & fíbrico \\
\hline & $40-50$ & $10 Y R$ 5/4 & 0,37 & 0,35 & 234 & 1,3 & 5 & 73 & fíbrico \\
\hline Média & & & $0,35 \mathrm{~B}$ & $0,29 \mathrm{~A}$ & $290 \mathrm{~A}$ & $4 \mathrm{~B}$ & $14 \mathrm{~B}$ & $65 \mathrm{~A}$ & \\
\hline Desvio-padrão & & & 0,05 & 0,04 & 78,52 & 3,70 & 14,72 & 8,03 & \\
\hline \multirow[t]{9}{*}{$\mathrm{P} 4$} & $0-10$ & $10 Y R 4 / 3$ & 0,32 & 0,18 & 361 & 9 & 44 & 52 & fíbrico \\
\hline & $10-20$ & $10 \mathrm{YR} 4 / 2$ & 0,32 & 0,21 & 294 & 7 & 34 & 32 & fíbrico \\
\hline & $20-30$ & 10YR $2 / 2$ & 0,34 & 0,26 & 313 & 5 & 23 & 36 & hêmico \\
\hline & $30-40$ & 10YR 2/1 & 0,37 & 0,29 & 247 & 5 & 22 & 10 & hêmico \\
\hline & $40-50$ & 10YR 2/1 & 0,41 & 0,33 & 216 & 6 & 20 & 16 & hêmico \\
\hline & $50-60$ & 10YR 3/2 & 0,37 & 0,30 & 256 & 5 & 19 & 16 & hêmico \\
\hline & $60-70$ & $10 Y R 3 / 3$ & 0,52 & 0,44 & 216 & 5 & 16 & 12 & hêmico \\
\hline & $70-80$ & 10YR $3 / 3$ & 0,41 & 0,33 & 233 & 5 & 20 & 16 & hêmico \\
\hline & $80-90$ & $10 Y R 2 / 2$ & 0,45 & 0,35 & 171 & 7 & 23 & 12 & sáprico \\
\hline Média & & & $0,39 B$ & $0,30 \mathrm{~A}$ & $256 \mathrm{~A}$ & $6 \mathrm{~B}$ & $25 \mathrm{~B}$ & $22 \mathrm{~B}$ & \\
\hline Desvio-padrão & & & 0,07 & 0,08 & 57,83 & 1,41 & 8,83 & 14,34 & \\
\hline
\end{tabular}

(1) Embrapa, 2006. ${ }^{(2)}$ Alef \& Nannipieri (1995). **: diferença significativa entre os perfis pelo teste de F a 1 \%. Médias seguidas da mesma letra nas colunas não diferem entre si pelo teste de Scheffé a $5 \%$. 
$\mathrm{O}$ valor de $\mathrm{DS}$ média de $\mathrm{P} 1$ é mais de três vezes maior (Quadro 2) e o seu teor médio de Corg é pelo menos três vezes menor $(p<0,01$ pelo teste $\mathrm{F}$ e $\mathrm{p}<0,05$ pelo teste de Scheffé - Quadro 3) do que, respectivamente, a DS e o Corg médios das demais turfeiras estudadas. Turfeiras são formadas em ambientes úmidos, que acumulam matéria orgânica (PontevedraPombal \& Martinez-Cortizas, 2004). De acordo com Pereira et al. (2005), em materiais orgânicos depositados em ambientes hidromórficos que têm a drenagem melhorada, a DS é elevada em relação a ambientes que permanecem saturados com água, pela compactação de seu material devido ao próprio peso; a aeração das camadas aumenta a velocidade de decomposição da matéria orgânica. Dessa forma, pode-se inferir que em P1 a melhoria das condições de drenagem - acelerada devido ao rebaixamento do leito do Córrego São Miguel pela mineração (Figura 2) - provocou elevação da DS média e diminuição do teor médio de Corg.

Os perfis $\mathrm{P} 2$ e $\mathrm{P} 4$ apresentaram maiores valores de Dmo e CMRA ( $p<0,01$ pelo teste F e $p<0,05$ pelo teste de Scheffé - Quadro 2) e menores valores da FM
( $p<0,01$ pelo teste $\mathrm{F}$ e $\mathrm{p}<0,05$ pelo teste de Scheffé Quadro 3). O modelo de equação de regressão que melhor explicou a variação da Dmo em função de Corg foi o exponencial $\left(R^{2}=0,8566\right)$, e da CMRA em função do Corg, o quadrático $\left(\mathrm{R}^{2}=0,6038\right)$; o coeficiente de correlação foi positivo e altamente significativo $(n=21$ e, respectivamente, $r=0,9255^{* *}, p<0,001$ e $r=$ $\left.0,7770^{* *}, \mathrm{p}<0,001\right)$. Assim, pode-se inferir que o teor e o estádio de decomposição da matéria orgânica influenciaram sua densidade e capacidade de retenção de água (fíbrico $\geq$ hêmico >> sáprico).

Os valores mais elevados de DS, RM e da relação FM/MO em P1 estão relacionados aos maiores teores da FM no perfil (média de 76,5 \% - Quadro 3) em que predomina a fração areia. As turfeiras $\mathrm{P} 2$ e $\mathrm{P} 4$ possuem menores teores médios de FM (respectivamente 17,6 e 29,0 - Quadro 3), em que há predomínio da fração silte. Consequentemente, esses perfis apresentam menores valores de DS, RM e relação FM/MO, estando sua matéria orgânica em estádio menos avançado de decomposição - são eles, respectivamente, fíbrico e hêmico (Quadro 2).

Quadro 3. Teores de carbono orgânico (Corg), fração mineral (FM), relação FM/MO, areia, argila e silte da FM de perfis de turfeiras da Serra do Espinhaço Meridional

\begin{tabular}{|c|c|c|c|c|c|c|c|}
\hline Perfil & Profundidade & $\mathrm{CO}^{(1)}$ & FM & FM/MO & Areia & Silte & Argila \\
\hline & $\mathrm{cm}$ & 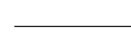 & dag kg ${ }^{-1}$ & 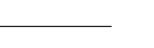 & 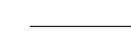 & $\%$ da FM & - \\
\hline \multirow[t]{7}{*}{$\mathrm{P} 1$} & $6-66$ & 13,3 & 72,6 & 2,65 & 94 & 5 & 1 \\
\hline & 80-116 & 12,6 & 68,3 & 2,15 & 97 & 3 & 0 \\
\hline & $118-122$ & 10,6 & 77,6 & 3,46 & 21 & 78 & 0 \\
\hline & $124-132$ & 12,5 & 77,6 & 3,46 & 76 & 3 & 21 \\
\hline & $140-150$ & 6,7 & 87,0 & 6,74 & 86 & 13 & 1 \\
\hline & $156-166$ & 12,9 & 76,9 & 3,33 & 91 & 9 & 0 \\
\hline & $170-174$ & 12,3 & 75,4 & 3,05 & 25 & 74 & 0 \\
\hline \multicolumn{2}{|l|}{ Média (1) } & $11,6 \mathrm{~B}^{* *}$ & $76,5 \mathrm{~A}^{* *}$ & $3,26 A^{* *}$ & $71 \mathrm{~A}^{\mathrm{NS}}$ & $26 \mathrm{~A}^{\mathrm{NS}}$ & $3 \mathrm{~A}^{\mathrm{NS}}$ \\
\hline \multicolumn{2}{|c|}{ Desvio-padrão } & 2,30 & 5,72 & 1,49 & 32,82 & 34,07 & 7,83 \\
\hline \multirow[t]{5}{*}{$\mathrm{P} 2$} & $0-10$ & 48,1 & 15,0 & 0,18 & 73 & 25 & 2 \\
\hline & $10-20$ & 48,1 & 13,4 & 0,15 & 0 & 95 & 5 \\
\hline & $20-30$ & 51,2 & 11,2 & 0,13 & 13 & 83 & 4 \\
\hline & $30-40$ & 43,9 & 15,6 & 0,18 & 25 & 71 & 4 \\
\hline & $40-50$ & 47,0 & 32,2 & 0,47 & 74 & 21 & 5 \\
\hline \multicolumn{2}{|l|}{ Média } & $47,7 \mathrm{~A}$ & $17,6 \mathrm{~B}$ & $0,21 \mathrm{~B}$ & $37 \mathrm{~A}$ & $59 \mathrm{~A}$ & $4 \mathrm{~A}$ \\
\hline \multicolumn{2}{|c|}{ Desvio-padrão } & 2,62 & 8,40 & 0,14 & 34,47 & 33,97 & 1,22 \\
\hline \multirow[t]{9}{*}{$\mathrm{P} 4$} & $0-10$ & 23,3 & 58,7 & 1,42 & 94 & 6 & 0 \\
\hline & $10-20$ & 28,7 & 49,6 & 0,98 & 61 & 38 & 1 \\
\hline & $20-30$ & 38,6 & 35,9 & 0,56 & 18 & 81 & 1 \\
\hline & $30-40$ & 43,3 & 22,5 & 0,29 & 05 & 95 & 0 \\
\hline & $40-50$ & 40,2 & 21,5 & 0,27 & 92 & 8 & 0 \\
\hline & $50-60$ & 44,3 & 18,7 & 0,23 & 43 & 2 & 55 \\
\hline & $60-70$ & 45,7 & 21,3 & 0,27 & 58 & 42 & 0 \\
\hline & $70-80$ & 45,4 & 17,5 & 0,21 & 39 & 59 & 2 \\
\hline & $80-90$ & 47,2 & 15,9 & 0,19 & 04 & 96 & 0 \\
\hline \multicolumn{2}{|l|}{ Média } & $39,6 \mathrm{~B}$ & $29,0 \mathrm{~B}$ & $0,41 \mathrm{~B}$ & $46 \mathrm{~A}$ & $47 \mathrm{~A}$ & $7 \mathrm{~A}$ \\
\hline \multicolumn{2}{|c|}{ Desvio-padrão } & 8,29 & 15,50 & 0,43 & 33,68 & 37,64 & 18,18 \\
\hline
\end{tabular}

(1) Corg: Embrapa (2006). **: diferença significativa entre os perfis pelo teste F a 1 \%. NS: diferença não significativa entre os perfis pelo teste F. Médias seguidas da mesma letra nas colunas não diferem entre si pelo teste de Scheffé a $5 \%$. 
Materiais fíbricos, ou seja, aqueles que possuem maiores teores de fibras esfregadas (FE), são menos decompostos e tendem a apresentar elevada porosidade (Conceição, 1989, citado por Pereira et al., 2005), composta de muitos macroporos, propiciando maiores valores de condutividade hidráulica. No processo de humificação e mineralização da matéria orgânica os macroporos colapsam, diminuindo o tamanho dos poros e também a porosidade total (Andriesse, 1988), o que pode elevar a CMRA, como observado em P2 e P4 (Quadro 2).

De acordo com a escala de decomposição de von Post (Stanek \& Silc, 1977), P2 e as duas primeiras camadas de $\mathrm{P} 4$ apresentam grande quantidade de fibras, material classificado como fíbrico (Embrapa, 2006), enquanto P1 apresenta camadas com matéria orgânica em estádio avançado de decomposição, denominadas sápricas, e $\mathrm{P} 4$ apresenta na maioria das camadas matéria orgânica em estádio intermediário de decomposição, denominadas hêmicas (Quadro 2). As elevadas relações FM/MO e os elevados teores de areia encontrados em P1, assim como as baixas relações FM/MO e os teores de silte encontrados na FM de P2 e P4 (Quadro 3), contribuem, respectivamente, para a drenagem moderada de $\mathrm{P} 1$ e a péssima drenagem de P2 e P4.

\section{Atributos químicos}

Nas turfeiras estudadas, o $\mathrm{pH}$ em água foi sempre maior em pelo menos uma unidade em relação ao $\mathrm{pH}$ em $\mathrm{CaCl}_{2}$ e, de acordo com Embrapa (2006), é extremamente ácido $(\mathrm{pH}<4,3)$ em $\mathrm{P} 2$, fortemente ácido $(4,3<\mathrm{pH}<5,3)$ em $\mathrm{P} 4$ e moderadamente ácido $(5,3<\mathrm{pH}<6,5)$ em $\mathrm{P} 1(\mathrm{p}<0,01$ pelo teste $\mathrm{F}$ e $\mathrm{p}<0,05$ pelo teste de Scheffé - Quadro 4). Esses valores de $\mathrm{pH}$ são semelhantes aos encontrados por Valladares et al. (2008) para Organossolos de quatro regiões do Brasil.

A saturação por alumínio (m) e os teores de $\mathrm{Al}^{3+}$ trocável apresentaram-se muito elevados e são diferentes estatisticamente entre os perfis $(\mathrm{p}<0,01$ pelo teste $\mathrm{F}$ e $\mathrm{p}<0,05$ pelo teste de Scheffé - Quadro 4). As fontes de $\mathrm{Al}^{3+}$ trocável são, provavelmente, os

Quadro 4. Alguns atributos químicos de perfis de turfeiras da Serra do Espinhaço Meridional

\begin{tabular}{|c|c|c|c|c|c|c|c|c|c|c|c|c|c|}
\hline \multirow{2}{*}{ Perfil } & \multirow{2}{*}{ Prof. } & \multicolumn{2}{|l|}{$\mathbf{p H}$} & \multirow{2}{*}{$\mathbf{P}$} & \multirow{2}{*}{$\mathbf{K}^{+}$} & \multirow{2}{*}{$\mathrm{Ca}^{2+}$} & \multirow{2}{*}{$\mathrm{Mg}^{2+}$} & \multirow{2}{*}{$\mathrm{Al}^{3+}$} & \multirow{2}{*}{$\mathbf{H}+\mathbf{A l}$} & \multirow{2}{*}{$\mathbf{S}$} & \multirow{2}{*}{ CTC } & \multirow{2}{*}{$\mathbf{m}$} & \multirow{2}{*}{ V } \\
\hline & & $\mathrm{CaCl}_{2}$ & $\mathrm{H}_{2} \mathrm{O}$ & & & & & & & & & & \\
\hline \multirow{8}{*}{$\mathrm{P} 1$} & $\mathrm{~cm}$ & & & \multicolumn{2}{|c|}{$-\mathrm{mg} \mathrm{kg}^{-1} \_$} & \multicolumn{6}{|c|}{$-\mathrm{cmol}_{\mathrm{c}} \mathrm{kg}^{-1}$} & \multicolumn{2}{|c|}{ - $\%$} \\
\hline & $6-66$ & 4,0 & 5,2 & 7,0 & 3,0 & 0,2 & 0,2 & 1,4 & 10,2 & 0,4 & 10,6 & 77 & 4 \\
\hline & $80-116$ & 4,0 & 5,3 & 7,1 & 3,0 & 0,3 & 0,2 & 1,1 & 7,3 & 0,5 & 7,8 & 68 & 7 \\
\hline & $118-122$ & 4,1 & 5,3 & 19,6 & 3,0 & 0,2 & 0,1 & 0,9 & 6,5 & 0,3 & 6,8 & 75 & 5 \\
\hline & $124-132$ & 4,1 & 5,2 & 52,7 & 3,0 & 0,2 & 0,1 & 0,6 & 6,5 & 0,3 & 6,8 & 66 & 5 \\
\hline & $140-150$ & 4,1 & 5,4 & 44,9 & 3,0 & 0,3 & 0,2 & 0,5 & 4,2 & 0,5 & 4,7 & 50 & 11 \\
\hline & $156-166$ & 4,3 & 5,4 & 51,0 & 3,0 & 0,3 & 0,3 & 1,0 & 8,1 & 0,6 & 8,7 & 62 & 7 \\
\hline & $170-174$ & 4,1 & 5,4 & 77,2 & 3,0 & 0,2 & 0,2 & 0,9 & 6,5 & 0,4 & 6,9 & 69 & 6 \\
\hline Média & & $4,1 \mathrm{~A}^{* *}$ & $5,3 \mathrm{~A}^{* *}$ & $37,1 \mathrm{~A}^{* *}$ & $3,01 \mathrm{~A}^{\mathrm{ns}}$ & $0,2 \mathrm{~B}^{* *}$ & $0,2 \mathrm{~B}^{* *}$ & $0,9 \mathrm{~B}^{* *}$ & $7,0 \mathrm{C}^{* *}$ & $0,4 \mathrm{~B}^{* *}$ & $7,5 \mathrm{C}^{* *}$ & $67 \mathrm{~B}^{* *}$ & $6 A^{* *}$ \\
\hline \multicolumn{2}{|c|}{ Desvio-padrão } & 0,10 & 0,09 & 26,51 & 0,00 & 0,05 & 0,07 & 0,30 & 1,83 & 0,11 & 1,84 & 8,98 & 2,30 \\
\hline \multirow[t]{5}{*}{$\mathrm{P} 2$} & $0-10$ & 2,8 & 4,2 & 4,6 & 8,0 & 0,8 & 0,8 & 2,4 & 67,2 & 1,6 & 68,8 & 60 & 2 \\
\hline & $10-20$ & 2,7 & 3,8 & 14,0 & 6,0 & 1,8 & 1,1 & 3,3 & 117,2 & 2,9 & 120,1 & 53 & 2 \\
\hline & $20-30$ & 2,8 & 3,8 & 19,5 & 24,0 & 2,2 & 1,1 & 3,6 & 117,2 & 3,4 & 120,6 & 52 & 3 \\
\hline & $30-40$ & 2,9 & 3,9 & 21,9 & 50,0 & 1,3 & 1,0 & 2,3 & 75,1 & 2,4 & 77,5 & 49 & 3 \\
\hline & $40-50$ & 2,7 & 3,8 & 18,7 & 11,0 & 2,6 & 1,0 & 3,9 & 146,4 & 3,6 & 150,0 & 52 & 2 \\
\hline Média & & $2,8 \mathrm{~B}$ & $3,9 \mathrm{C}$ & $15,7 \mathrm{AB}$ & $19,8 \mathrm{~A}$ & $1,7 \mathrm{~A}$ & $1,0 \mathrm{~A}$ & $3,1 \mathrm{~B}$ & $104,6 \mathrm{~A}$ & $2,8 \mathrm{~A}$ & $107,4 \mathrm{~A}$ & $53,2 \mathrm{C}$ & $2,4 \mathrm{~B}$ \\
\hline \multicolumn{2}{|c|}{ Desvio-padrão } & 0,08 & 0,17 & 6,86 & 18,28 & 0,71 & 0,12 & 0,72 & 32,92 & 0,81 & 33,67 & 4,09 & 0,55 \\
\hline \multirow[t]{9}{*}{$\mathrm{P} 4$} & $0-10$ & 4,4 & 4,7 & 4,6 & 88,0 & 0,3 & 0,2 & 2,2 & 22,1 & 0,7 & 22,8 & 75 & 3 \\
\hline & $10-20$ & 4,5 & 4,6 & 6,9 & 64,0 & 0,6 & 0,3 & 2,7 & 38,6 & 1,1 & 39,7 & 72 & 3 \\
\hline & $20-30$ & 3,9 & 5,3 & 8,2 & 38,0 & 0,3 & 0,2 & 4,7 & 34,5 & 0,6 & 35,1 & 89 & 2 \\
\hline & $30-40$ & 3,8 & 4,7 & 5,3 & 5,0 & 0,4 & 0,2 & 7,1 & 43,1 & 0,6 & 43,7 & 92 & 1 \\
\hline & $40-50$ & 3,9 & 4,7 & 4,4 & 6,0 & 0,2 & 0,2 & 7,6 & 43,1 & 0,4 & 43,5 & 95 & 1 \\
\hline & $50-60$ & 3,8 & 4,6 & 3,4 & 5,0 & 0,2 & 0,2 & 7,8 & 38,6 & 0,4 & 39,0 & 95 & 1 \\
\hline & $60-70$ & 3,9 & 4,6 & 2,7 & 3,0 & 0,2 & 0,2 & 6,8 & 43,1 & 0,4 & 43,5 & 94 & 1 \\
\hline & $70-80$ & 3,9 & 4,4 & 2,4 & 2,0 & 0,2 & 0,1 & 8,9 & 43,1 & 0,3 & 43,4 & 97 & 1 \\
\hline & $80-90$ & 3,8 & 4,0 & 1,5 & 3,0 & 0,2 & 0,2 & 12,0 & 43,1 & 0,4 & 43,5 & 97 & 1 \\
\hline Média & & $4,0 \mathrm{~A}$ & $4,6 \mathrm{~B}$ & $4,4 \mathrm{~B}$ & $23,8 \mathrm{~A}$ & $0,3 \mathrm{~B}$ & $0,2 \mathrm{~B}$ & $6,6 \mathrm{~A}$ & $38,8 \mathrm{~B}$ & $0,5 \mathrm{~B}$ & $39,4 \mathrm{~B}$ & $89,6 \mathrm{~A}$ & $1,6 \mathrm{~B}$ \\
\hline Desvio- & & 0,27 & 0,34 & 2,17 & 32,22 & 0,14 & 0,05 & 2,75 & 6,98 & 0,25 & 6,88 & 9,46 & 0,88 \\
\hline
\end{tabular}

pH em água - relação 1:2,5; P e K - Extrator Mehlich-1; Ca, $\mathrm{Mg}$ e Al - extrator $\mathrm{KCl} 1 \mathrm{~mol} \mathrm{~L}^{-1} ; \mathrm{H}+\mathrm{Al}$ (Acidez Potencial) - extrator acetato de cálcio $0,5 \mathrm{~mol} \mathrm{~L}^{-1}$; S: soma de bases; CTC: capacidade de troca de cátions a $\mathrm{pH}$ 7; m: saturação por alumínio; V: saturação por bases. **: diferença significativa entre os perfis pelo teste $\mathrm{F}$ a $1 \%$. ${ }^{\text {NS}}$ : diferença não significativa entre os perfis pelo teste F. Médias seguidas da mesma letra nas colunas não diferem entre si pelo teste de Scheffé a $5 \%$. 
feldspatos dos filitos e das rochas básicas do Supergrupo Espinhaço (Silva et al., 2005a). O Al ${ }^{3+}$ trocável permanece elevado nas turfeiras, provavelmente devido à sua associação com a matéria orgânica (Buurman \& Breemen, 2002). O modelo de equação de regressão que melhor explicou a variação do $\mathrm{Al}^{3+}$ em função do Corg foi o exponencial $\left(\mathrm{R}^{2}=\right.$ 0,7506), sendo o coeficiente de correlação positivo e altamente significativo $(\mathrm{n}=21 ; \mathrm{r}=0,8663 * *$; $\mathrm{p}<0,001)$.

A acidez potencial foi mais baixa em $\mathrm{P} 1$ e decresceu no perfil até os $150 \mathrm{~cm}$. Em P2 os valores foram crescentes até os $20 \mathrm{~cm}$, e em $\mathrm{P} 4$, mais homogêneos ao longo do perfil. De acordo com Silva et al. (2007, 2008), os valores da acidez potencial estão fortemente relacionados com o teor de Corg dos perfis. A turfeira P1, que apresenta o mais baixo teor de Corg (Quadro 6), também possui a menor acidez potencial, ao passo que P2 apresenta elevados teores de Corg (Quadro 6) e de acidez potencial. Os teores de alumínio trocável são muito elevados em $\mathrm{P} 4$, com valores que chegam a $12,0 \mathrm{cmol}_{\mathrm{c}} \mathrm{kg}^{-1}$, e as diferenças entre $\mathrm{P} 4$ e os demais perfis estudados são estatisticamente significativas $(p<0,01$ pelo teste $\mathrm{F}$ e $\mathrm{p}<0,05$ pelo teste de Scheffé Quadro 4). Benites (2001) trabalhou com solos de altitude em Minas Gerais, encontrando também valores de $\mathrm{Al}$ trocável muito elevados, o que favorece o acúmulo de material orgânico, pois inibe a atividade biológica (Buurman \& Breemen, 2002; Pereira et al., 2005).

A saturação por bases é baixa, com o predomínio de $\mathrm{H}^{+}$no complexo sortivo desses solos (Quadro 4). A soma de bases (S) em P1 é muito baixa, evidenciando a baixa disponibilidade de nutrientes, e mais elevada em P2, chegando a 3,6 $\mathrm{cmol}_{\mathrm{c}} \mathrm{kg}^{-1}$ de solo abaixo dos $40 \mathrm{~cm}$. As diferenças verificadas entre os valores médios de $\mathrm{S}$ das turfeiras estudadas são estatisticamente significativas ( $p<0,01$ pelo teste $\mathrm{F}$ e p $<0,05$ pelo teste de Scheffé - Quadro 4).

A capacidade de troca catiônica (CTC) é baixa em P1 e muito elevada em P2 e P4, alcançando $150 \mathrm{cmol}_{\mathrm{c}} \mathrm{kg}^{-1}$ de solo em P2; as diferenças são estatisticamente significativas $(p<0,01$ pelo teste $F$ e p < 0,05 pelo teste de Scheffé - Quadro 4). Os valores de CTC estão relacionados à quantidade de matéria orgânica do solo (Resende et al., 1999; Pereira et al., 2005). No presente estudo, o modelo de equação de regressão que melhor explicou a variação da CTC em função do Corg foi o exponencial $\left(R^{2}=0,8347\right)$, e o coeficiente de correlação é positivo e altamente significativo $\left(n=21 ; r=0,9136^{* *} ; p<0,001\right)$.

Os resultados deste trabalho indicam que estádio de decomposição e, principalmente, o grau de humificação da matéria orgânica também poderiam influenciar a CTC, uma vez que P2 e P4 apresentam elevados teores de Corg, que não diferem entre si estatisticamente (Quadro 3), porém a CTC de P2 (fíbrico) é quase três vezes maior do que a de $\mathrm{P} 4$ (hêmico). O valor da CTC por unidade de Corg para
$\mathrm{P} 1, \mathrm{P} 2$ e $\mathrm{P} 4$ é de, respectivamente, $0,55,2,25$ e $0,95 \mathrm{cmol}_{\mathrm{c}} \mathrm{kg}^{-1}$ de solo. A substância humica predominante de $\mathrm{P} 1$ é o ácido fúlvico, enquanto em P2 e P4 a humina predomina amplamente (Silva et al., 2009b). As cargas elétricas da matéria orgânica estão relacionadas aos grupos funcionais das substâncias humicas e podem variar bastante (Breemen \& Buurman, 2002). Mckay \& Porter (1997) afirmam haver boa correlação entre ácidos poliurônicos não esterificados nas turfeiras e sua capacidade de troca de cátions. Franchi (2004) afirma que prétratamentos ácidos podem ser empregados para elevar a CTC das turfeiras. Smith et al. (1977) realizaram pré-tratamentos nas turfeiras com ácidos fosfórico e sulfúrico e obtiveram sensível aumento da CTC. Dessa forma, os mais elevados valores para a CTC de P2 podem estar relacionados com sua constituição química, que por sua vez é influenciada pelo estádio de decomposição e pelo seu $\mathrm{pH}$, mais baixo entre os perfis estudados. Esses resultados demonstram a necessidade de realizar novos estudos para verificar a influência do estádio de decomposição e, principalmente, da constituição química da matéria orgânica na CTC.

De acordo com Andriesse (1988) e Galvão \& Vahl (1996), a composição química dos solos orgânicos é influenciada diretamente pela fração mineral, pela natureza do material orgânico, pelo grau de decomposição da matéria orgânica e pela composição química da água de formação, o que contribui para que ocorra ampla variação na composição mineral desses solos entre si e entre os horizontes de um mesmo solo. Essas constatações são corroboradas no presente trabalho, uma vez que P1 corresponde a um Organossolo Háplico Sáprico térrico (Embrapa, 2006), com mais baixos teores de matéria orgânica, em relação aos demais perfis estudados (Quadro 2), e teores de areia elevados (Quadro 3); P2 corresponde a um Organossolo Háplico Fíbrico típico (Embrapa, 2006), com elevados teores de Corg e menor taxa de decomposição da matéria orgânica (Quadro 2) e predomínio da fração silte na fração mineral (Quadro 3); e P4 corresponde a um Organossolo Háplico Hêmico típico (Embrapa, 2006), com matéria orgânica em estádio intermediário de decomposição e teores médios de areia e silte equivalentes entre si na FM. Entre e dentro de todos os perfis, os teores de areia e de silte variaram amplamente, enquanto os teores de argila foram, no geral, muito baixos (Quadro 3), de forma que a influência da fração argila na CTC é praticamente nula.

Os teores de $\mathrm{Cu}, \mathrm{Zn}$ e Mn são mais elevados em $\mathrm{P} 2$; os de Ti e Zr, em P1; e os de Fe, em P4. As diferenças entre os teores desses elementos, com exceção do $\mathrm{Fe}$, nos perfis são estatisticamente significativas $(p<0,01$ pelo teste $F$ e $p<0,05$ pelo teste de Scheffé - Quadro 5). Em P1, o teor dos elementos analisados tende a variar em profundidade, possivelmente devido a diferenças na composição granulométrica das camadas morfologicamente 
diferenciadas (Quadro 3). Em P2, os teores de Zn, Mn, e Fe diminuem e os teores de $\mathrm{Pb}$, Ti e $\mathrm{Zr}$ aumentam com a profundidade. Em P4, os teores de $\mathrm{Zn}, \mathrm{Fe}, \mathrm{Pb}$, $\mathrm{Ti}$ e $\mathrm{Zr}$ diminuem, e o teor de Mn aumenta com a profundidade. Ti e Zr são elementos de baixa mobilidade (Drees \& Wilding, 1973) e tendem a se concentrar no perfil do solo com o passar do tempo. As diferenças encontradas em relação aos teores dos elementos de elevado potencial redox ( $\mathrm{Fe}$ e $\mathrm{Mn}$ ) entre e dentro dos perfis estudados evidenciam diferenças no regime hídrico dessas turfeiras, uma vez que no estado reduzido esses elementos apresentam elevada mobilidade. $\mathrm{O} \mathrm{Cu}$ e o $\mathrm{Pb}$ apresentam grande afinidade com a matéria orgânica (Buurman \& Breemen, 2002) e, dessa forma, suas concentrações tenderiam a ser mais elevadas em P2 e P4, que apresentam teores mais elevados de Corg em relação a P1 $(p<0,01$ pelo teste $\mathrm{F} \mathrm{e} \mathrm{p}<0,05$ pelo teste de Scheffé - Quadro 3). Entretanto, os dados do quadro 5 não corroboram essa tendência, pois os teores de $\mathrm{Pb}$ são mais elevados em $\mathrm{P} 1$, seguido de $\mathrm{P}$ 4, enquanto os teores de $\mathrm{Cu}$ são mais elevados em P2, seguido de P1.
A variação do estádio de decomposição da matéria orgânica ( $\mathrm{P} 1$ - sáprico, $\mathrm{P} 2$ - fíbrico e $\mathrm{P} 4$ - hêmico), da drenagem dos perfis ( $\mathrm{P} 1$ - moderadamente drenado; P2 e P4 muito mal drenados), da altitude (Quadro 1) e, provavelmente, da idade radiocarbônica e de deposições atmosféricas desses elementos, naturais ou antrópicas, também influencia os teores dos elementos analisados entre e dentro dos perfis analisados. Como a drenagem atual de P1 é moderada e a mineração de diamante rebaixou o nível freático local, pode-se inferir que o acúmulo de matéria orgânica se deu antes da chegada dos garimpeiros. O rebaixamento do lençol freático proporcionou a melhoria das condições de drenagem, elevando a Ds e acelerando a decomposição da matéria orgânica (Pereira et al., 2005), contribuindo assim para aumentar proporcionalmente o teor de areia neste perfil, devido ao seu acúmulo residual e a aportes eólicos, e alterar os teores dos elementos analisados.

Trabalhos realizados em turfeiras por Shotyk et al. (1997, 1998), Martinez-Cortizas et al. (1997, 1999), Jedrysek et al. (2003) e Espi et al. (1997) em vários

Quadro 5. Teores de $\mathrm{Cu}, \mathrm{Zn}, \mathrm{Mn}, \mathrm{Fe}, \mathrm{Pb}$, Ti e $\mathrm{Zr}$ na terra fina seca ao ar de perfis de turfeiras da Serra do Espinhaço Meridional

\begin{tabular}{|c|c|c|c|c|c|c|c|c|c|c|}
\hline Perfil & Profundidade & $\mathrm{Cu}$ & $\mathbf{Z n}$ & Mn & $\mathbf{F e}$ & $\mathbf{P b}$ & $\mathrm{Ti}$ & $\mathrm{Zr}$ & Al & $\mathrm{Pb} / \mathrm{Al}$ \\
\hline & $\mathrm{cm}$ & & & & - & $\mathrm{mg} \mathrm{kg}^{-1}$ & & & & \\
\hline \multirow[t]{7}{*}{$\mathrm{P} 1$} & $6-66$ & 12 & 6 & 28 & 3.770 & 60 & 21.177 & 996 & & \\
\hline & $80-116$ & 10 & 7 & 18 & 1.956 & 45 & 13.511 & 798 & & \\
\hline & $118-122$ & 24 & 9 & 18 & 2.650 & 49 & 17.850 & 950 & & \\
\hline & $124-132$ & 32 & 9 & 23 & 1.900 & 37 & 15.300 & 971 & & \\
\hline & $140-150$ & 17 & 8 & 17 & 2.060 & 18 & 9.860 & 911 & & \\
\hline & $156-166$ & 21 & 7 & 15 & 4.360 & 28 & 15.100 & 889 & & \\
\hline & $170-174$ & 26 & 8 & 13 & 6.050 & 30 & 14.400 & 982 & & \\
\hline \multicolumn{2}{|l|}{ Média } & $20 \mathrm{~B}^{* *}$ & $8 \mathrm{~B}^{* *}$ & $19 \mathrm{~B}^{* *}$ & $3.249 \mathrm{~A}^{\mathrm{ns}}$ & $38 \mathrm{~A}^{* *}$ & $15.314 \mathrm{~A}^{* *}$ & $928 \mathrm{~A}^{* *}$ & & \\
\hline \multicolumn{2}{|c|}{ Desvio-padrão } & 7,85 & 1,11 & 5,08 & $1.560,74$ & 14,25 & $3.528,09$ & 69,02 & & \\
\hline \multirow[t]{5}{*}{$\mathrm{P} 2$} & $0-10$ & 33 & 53 & 100 & 2.694 & 4 & 396 & 9 & 1.515 & 0,0023 \\
\hline & $10-20$ & 28 & 26 & 51 & 2.524 & 2 & 279 & 5 & 1.302 & 0,0019 \\
\hline & $20-30$ & 35 & 29 & 33 & 2.426 & 3 & 622 & 16 & 1.369 & 0,0020 \\
\hline & $30-40$ & 53 & 27 & 28 & 2.054 & 4 & 2.163 & 42 & 3.752 & 0,0012 \\
\hline & $40-50$ & 35 & 23 & 33 & 2.019 & 11 & 6.067 & 181 & 13.851 & 0,0008 \\
\hline \multicolumn{2}{|l|}{ Média } & $37 \mathrm{~A}$ & $32 \mathrm{~A}$ & $49 \mathrm{~A}$ & $2.343 \mathrm{~A}$ & $5 \mathrm{~B}$ & $1.905 \mathrm{~B}$ & $51 \mathrm{~B}$ & $4.358 \mathrm{~B}^{* *}$ & $0,0016 \mathrm{~A}^{\mathrm{NS}}$ \\
\hline \multicolumn{2}{|c|}{ Desvio-padrão } & 9,50 & 12,16 & 29,82 & 296,37 & 3,56 & $2.447,24$ & 74,31 & $5.404,63$ & 0,0006 \\
\hline \multirow[t]{9}{*}{$\mathrm{P} 4$} & $0-10$ & 13 & 24 & 5 & 12.700 & 44 & 8.961 & 251 & 26.233 & 0,0017 \\
\hline & $10-20$ & 15 & 20 & 5 & 11.900 & 42 & 8.070 & 211 & 17.090 & 0,0024 \\
\hline & $20-30$ & 15 & 16 & 5 & 10.600 & 30 & 3.285 & 81 & 6.933 & 0,0044 \\
\hline & $30-40$ & 15 & 13 & 14 & 3.900 & 9 & 1.995 & 53 & 9.058 & 0,0035 \\
\hline & $40-50$ & 14 & 9 & 17 & 1.100 & 4 & 1.602 & 45 & 13.172 & 0,0003 \\
\hline & $50-60$ & 15 & 9 & 21 & 1.000 & 4 & 1.585 & 42 & 14.392 & 0,0003 \\
\hline & $60-70$ & 17 & 8 & 17 & 900 & 4 & 1.510 & 44 & 14.710 & 0,0003 \\
\hline & $70-80$ & 16 & 7 & 21 & 600 & 9 & 1.559 & 41 & 13.822 & 0,0006 \\
\hline & $80-90$ & 13 & 4 & 20 & 600 & 9 & 1.811 & 52 & 10.252 & 0,0009 \\
\hline \multicolumn{2}{|l|}{ Média } & $15 \mathrm{~B}$ & $12 \mathrm{~B}$ & $14 \mathrm{~B}$ & $4.811 \mathrm{~A}$ & 17B & $3.375 \mathrm{~B}$ & $91 \mathrm{~B}$ & $13.962 \mathrm{~A}$ & $0,0016 \mathrm{~A}$ \\
\hline \multicolumn{2}{|c|}{ Desvio-padrão } & 1,30 & 6,59 & 7,03 & $5.313,77$ & 16,66 & $2.973,40$ & 80,85 & $5.578,64$ & 0,0015 \\
\hline
\end{tabular}

$\mathrm{Cu}, \mathrm{Zn}, \mathrm{Mn}, \mathrm{Fe}, \mathrm{Pb}$, Ti e Zr determinados por fluorescência de raios X, pela técnica EMMA - Energy Dispersive Miniprobe Multielement Analyser (Cheburkin \& Shotyk, 1996). ** Diferença significativa entre os perfis pelo teste F a $1 \%$. NS Diferença não significativa entre os perfis pelo teste F. Médias seguidas da mesma letra nas colunas não diferem entre si pelo teste de Scheffé a $5 \%$. 
países dos dois hemisférios relacionam esses pedoambientes com a evolução das paisagens, as mudanças climáticas e a deposição atmosférica de metais pesados. As variações nos teores de $\mathrm{Pb}$ foram relacionadas à queima de combustíveis fósseis (Espi et al., 1997) e ao teor de $\mathrm{Pb}$ na gasolina, o qual, no Brasil, foi retirado somente em 1989 (Portal BR, 2008). A concentração de $\mathrm{Pb}$ nos perfis estudados provavelmente está relacionada à localização desses perfis. $\mathrm{O}$ teor de $\mathrm{Pb}$ é mais elevado nas duas primeiras camadas de $\mathrm{P} 1$ e nas três primeiras camadas de $\mathrm{P} 4$, enquanto em $\mathrm{P} 2$ os teores de $\mathrm{Pb}$ são muito baixos e aumentam apenas na última camada (Quadro 5). Como P1 e P4 estão localizados nas proximidades da BR 367 e P2 localiza-se no Parque Estadual do Pico do Itambé, a $1.800 \mathrm{~m}$ de altitude, a cerca de $20 \mathrm{~km}$ em linha reta de rodovia pavimentada, situada abaixo da cota $1.000 \mathrm{~m}$, pode-se inferir que os teores mais elevados de $\mathrm{Pb}$ nas primeiras camadas de $\mathrm{P} 1$ e $\mathrm{P} 4$ provavelmente estão relacionados ao $\mathrm{Pb}$ da gasolina.

Espi et al. (1997), Martinez-Cortizas et al. (1997, 1999) e Shotky et al. (1998) relacionaram teores mais elevados de $\mathrm{Pb}$ nas camadas superficiais de turfeiras localizadas, respectivamente, na Bolívia, Espanha e Suíça com o uso de gasolina como combustível de veículos no século XX. Martinez-Cortizas et al. (1997) e Shotky et al. (1998) detectaram, inclusive, diminuição do teor de $\mathrm{Pb}$ das camadas superficiais em relação àquelas abaixo de $5 \mathrm{~cm}$ e relacionaram-na com a retirada do $\mathrm{Pb}$ da gasolina, a partir da década de 1970 do século XX, na Europa. O Pb não é nutriente de plantas e, de acordo com Adriano (1985), sua concentração em vegetais independe do substrato. Partindo dessa premissa, Espi et al. (1997) utilizaram a relação $\mathrm{Pb} / \mathrm{Al}$ para testar o enriquecimento natural em relação ao enriquecimento antrópico de $\mathrm{Pb} \mathrm{em}$ turfeira da Bolívia e relacionaram os mais elevados valores da relação $\mathrm{Pb} / \mathrm{Al}$ na superfície à poluição, principalmente ao incremento do uso da gasolina como combustível. No presente trabalho, a relação $\mathrm{Pb} / \mathrm{Al}$ (Quadro 5) também é muito mais elevada até $40 \mathrm{~cm}$ de profundidade, notadamente em $\mathrm{P} 4$, o que pode estar relacionado ao uso de gasolina como combustível. No entanto, outros trabalhos deverão ser realizados para comprovar essa hipótese.

\section{Atributos microbiológicos}

Cerri \& Volkoff (1988) consideraram a presença de bases fator primordial no processo de humificação da matéria orgânica do solo, já que baixos teores de cátions trocáveis implicam uma baixa atividade biológica. O perfil $\mathrm{P} 1$ possui, além da drenagem moderada, os valores mais baixos de S e CTC, e as diferenças entre os valores de $\mathrm{S}$ dos perfis são estatisticamente significativas ( $p<0,01$ pelo teste $\mathrm{F}$ e p $<0,05$ pelo teste de Scheffé - Quadro 4). Esses fatores em conjunto propiciaram baixa atividade biológica em P1, que apresentou os menores valores médios de respiração basal (Rbasal) e C da biomassa microbiana (Cmic), sendo as diferenças estatisticamente significativas $(p<0,01$ pelo teste $\mathrm{F}$ e $\mathrm{p}<0,05$ pelo teste de Scheffé - Quadro 6). Este perfil também apresenta numericamente os mais elevados valores do quociente metabólico - $\mathrm{qCO}_{2}$, uma vez que elevada taxa de Rbasal indica maior atividade microbiana e uma decomposição mais rápida do material orgânico do solo (Carter, 1986), e um maior valor de $\mathrm{qCO}_{2}$ indica que a população microbiana está apresentando elevado gasto de energia na sua manutenção, mediante altas taxas de respiração (Dias-Júnior, 1998).

Nos perfis $\mathrm{P} 2$ e $\mathrm{P} 4$ os valores médios de Rbasal e Cmic são muito superiores, e o $\mathrm{qCO}_{2}$ é mais baixo em relação a P1. Teores mais elevados de Corg (Quadro 3) favorecem a atividade biológica (Buurman \& Breemen, 2002). O modelo de equação de regressão que melhor explicou a variação do Cmic em função do Corg foi o exponencial $\left(R^{2}=0,5988\right)$, e o coeficiente de correlação é positivo e altamente significativo $(\mathrm{n}=21 ; \mathrm{r}=$ $0,7700 * * ; p<0,001)$. Dessa forma, as turfeiras P2 e $\mathrm{P} 4$ apresentam atividade biológica mais intensa. Como a microbiota respira a elevadas taxas para se manter nesses pedoambientes saturados com água o ano todo, as elevadas taxas de respiração fornecem a energia para a manutenção do metabolismo da atividade biológica (Dias-Júnior, 1998), garantindo sua sobrevivência em condições adversas.

A biomassa microbiana é um compartimento da matéria orgânica do solo diretamente influenciado por fatores bióticos e abióticos, sendo, portanto, sensível às mudanças ocorridas no sistema (Gama-Rodrigues, 2005). Em P2, a Rbasal e o $\mathrm{qCO}_{2}$ são mais elevados na primeira camada (Quadro 6), onde também são encontrados os teores mais elevados de $\mathrm{Cu}$ e $\mathrm{Zn}$ (Quadro 5). Em P4, a Rbasal e o $\mathrm{qCO}_{2}$ são mais elevados nas duas primeiras camadas, nas quais os teores de $\mathrm{Zn}$ e $\mathrm{Pb}$ também são mais elevados (Quadro 5). Como P2 e P4 situam-se em ambientes muito mal drenados, pode-se inferir que nas camadas superficiais de $\mathrm{P} 2$ os teores mais elevados de $\mathrm{Cu}, \mathrm{Zn}$, Mn e Ti e, nas camadas superficiais de P4, os teores mais elevados de $\mathrm{Pb}, \mathrm{Zn}$ e $\mathrm{Zr}$ de alguma forma contribuem para a elevação do gasto de energia pela população microbiana para sua manutenção, mediante altas taxas de respiração (Dias-Júnior, 1998)

\section{Relações das condições de drenagem e do clima com atributos e classificação das turfeiras}

A turfeira com a matéria orgânica em estádio mais avançado de decomposição- $\mathrm{P} 1$ situa-se na mais baixa altitude $(1.250 \mathrm{~m})$, onde as temperaturas médias anuais são mais elevadas em relação aos demais locais estudados e as condições de drenagem são moderadas, proporcionadas pela ação antrópica. Segundo Fritzons et al. (2008), a temperatura do ar é influenciada também pela altitude, latitude e longitude e, normalmente, decresce com a elevação da altitude numa proporção de aproximadamente $1{ }^{\circ} \mathrm{C} / 100 \mathrm{~m}$ (gradiente adiabático do ar seco). A turfeira P1 apresenta menor teor de Corg, atividade biológica 


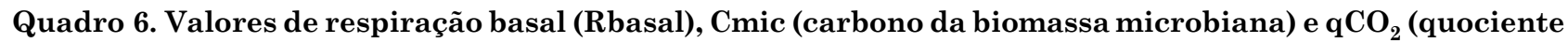
metabólico) de perfis de turfeiras da Serra do Espinhaço Meridional

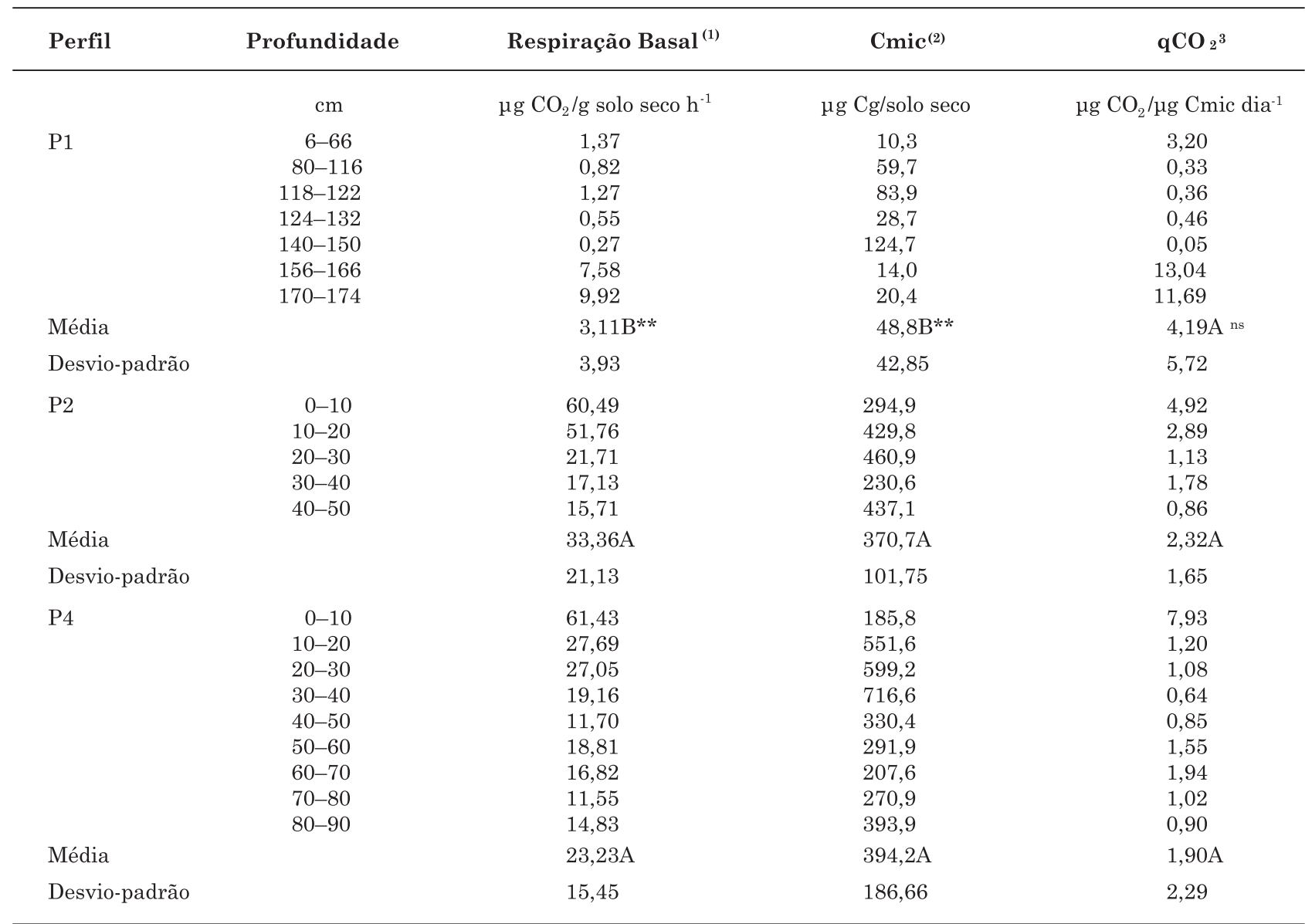

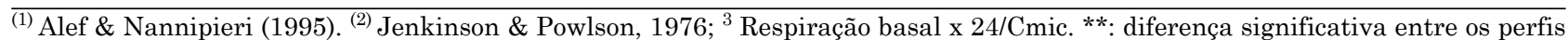
pelo teste $\mathrm{F}$ a $1 \%$. ${ }^{\mathrm{NS}}$ : diferença não significativa entre os perfis pelo teste $\mathrm{F}$. Médias seguidas da mesma letra nas colunas não diferem entre si pelo teste de Scheffé a $5 \%$.

menos intensa, maior contribuição da FM e maiores teores de $\mathrm{Pb}$, Ti e Zr. Situa-se em área antropizada e foi classificada como Organossolo Háplico Sáprico térrico (Embrapa, 2006).

A turfeira com a matéria orgânica em estádio de decomposição menos acentuado - P2 situa-se na altitude mais elevada $(1.800 \mathrm{~m})$, onde as temperaturas médias anuais são mais baixas em relação aos demais locais estudados e as condições de drenagem são muito ruins. Apresenta o maior teor de Corg, atividade biológica mais intensa, pouca contribuição da FM e situa-se em área não antropizada. Foi classificada como Organossolo Háplico Fíbrico típico (Embrapa, 2006).

A turfeira P4 apresenta matéria orgânica em estádio intermediário de decomposição e situa-se a $1.350 \mathrm{~m}$ de altitude, a cerca de $4 \mathrm{~km}$ de Diamantina, às margens de uma rodovia pavimentada. Suas condições de drenagem também são muito más, seus teores de Corg são elevados e a atividade biológica é intensa. Apresenta teor médio de $\mathrm{Pb}$ sete vezes mais elevado nas camadas superficiais em relação às mais profundas, o que foi relacionado com sua localização próximo à rodovia $\mathrm{BR} 367$. Foi classificada como Organossolo Háplico Hêmico típico (Embrapa, 2006).

\section{CONCLUSÕES}

1. A localização, a altitude e a drenagem influenciam os atributos morfológicos, físicos, químicos e biológicos das turfeiras da SdEM.

2. O teor de metais pesados está relacionado com o teor e a composição granulométrica da FM e com a localização das turfeiras.

\section{AGRADECIMENTOS}

À Fundação de Amparo à Pesquisa do Estado de Minas Gerais - FAPEMIG, pelo apoio financeiro para execução de parte deste trabalho, ao IEF/MG (Parques 
Estaduais do Biribiri e do Pico do Itambé) e à COPASA (APA Pau-de-Fruta).

\section{LITERATURA CITADA}

ADRIANO, D.C. Trace elements in the terrestrial environment. New York, Springer Verlag, 1986. 533p.

ALEF, K. \& NANNIPIERI, P. Methods in applied soil microbiology and biochemistry. London, Academic Press, 1995. 648p.

ANDRIESSE, J.P. Nature and management of tropical peat soils. Rome, FAO, 1988. (FAO Soils Bulletin, 59)

AUGUSTIN, C.H.R.R. Amphitheaters and hollows with depositional sequences and their significance on the evolution of tropical landscape. In: INTERNATIONAL SEDIMENTOLOGICAL CONGRESS, 14., Recife, 1994. Proceedings... Recife, 1994. p.G5 and G6.

BUURMAN, P. \& BREEMEN, N. Soil formation. 2.ed. Dordrecht, Kluwer Academic Publishers, 2002. 404p.

BENITES, V.M.; SCHAEFER, C.E.G.R.; MENDONÇA,E.S. \& MARTIN NETO, L. Caracterização da matéria orgânica e micromorfologia de solos sob campos de altitude no Parque Estadual da Serra do Brigadeiro (MG). R. Bras. Ci. Solo, 25:661-674, 2001.

CARTER, M.R. Microbial biomass as an index for tillage induced changes in soil biological properties. Soil Till. Res., 7:29-40, 1986.

CERRI, C.C. \& VOLKOFF, B. Matéria orgânica de três solos dos campos inundáveis da Ilha de Marajó/PA. R. Bras. Ci. Solo, 12:93-100, 1988

CHEBURKIN, A.K. \& SHOTYK, W. An energy-dispersive Miniprobe Multielement Anayser (EMMA) for direct analysis of $\mathrm{Pb}$ and other trace elements in peats. Freseniu's J. Anal. Chem., 354:688-691,1996.

CONCEIÇÃO, M.; FREIXO, A.A.; ARAÚJO, W.S.; CUNHA, T.J.F.; MARTIN NETO, L. \& SAAB, S.C. Caracterização das substâncias em solos orgânicos do estado do Rio de Janeiro, sob diversas atividades agrícolas. Rio de Janeiro, Embrapa Solos, 1999 (Pesquisa em Andamento - Embrapa Solos, 5)

DIAS-JÚNIOR, H.E.; MOREIRA, F.M.S.; SIQUEIRA, J.O. \& SILVA, R. Metais pesados, densidade e atividade microbiana em solo contaminado por rejeitos de indústria de zinco. R. Bras. Ci. Solo, 22:631-640, 1998

DREES, L.R. \& WILDING, L.P. Elemental variability within a sampling unit. Soil Sci.Soc. Am. Proc., 37:82-87, 1973.

DOCE. Directiva 92/43/CEE del Consejo de Conservation de Hábitats Naturales y de la Fauna y Flora Silvestres. (DOCE, 2060)

EMPRESA BRASILEIRA DE PESQUISA AGROPECUÁRIA EMBRAPA. Levantamento de reconhecimento dos solos do estado do Espírito Santo. Rio de Janeiro, Centro Nacional de Pesquisa de Solos, 1978. 379p. (Boletim Técnico, 45)
EMPRESA BRASILEIRA DE PESQUISA AGROPECUÁRIA EMBRAPA. Centro Nacional de Pesquisa de Solos. Sistema brasileiro de classificação de solos. Brasília, Embrapa Produção de Informação; Rio de Janeiro, Embrapa Solos, 2006. 312p.

EMPRESA BRASILEIRA DE PESQUISA AGROPECUÁRIA EMBRAPA. Centro Nacional de Pesquisa de Solos. Manual de métodos de análises de solos. Campinas, 1997. 212p.

ESPI, E.; BOUTRON, C.F.; HONG, S.; POURCHET, M.; FERRARI, C.; SHOTYK, W. \& CHARLET, L. Changing concentrations of $\mathrm{Cu}, \mathrm{Zn}, \mathrm{Cd}$ and $\mathrm{PB}$ in a hight altitude peat bog from Bolivia during the past tree centuries. Water, Air Soil Poll., 100:289-296, 1997.

FAO -UNESCO. Soil Map of the World at scale 1:5.000.000. In: WORD CONGRESS OF SOIL SCIENCE, 14., Kyoto, 1990. Proceedings. Kyoto, International Soil Science Society, 1990.

FRANCHI, J.G. A utilização de turfa como adsorvente de metais pesados. São Paulo, Universidade de São Paulo, 2004. 187p. (Tese de Doutorado)

FRITZONS, E.; MANTOVANI, L.E. \& AGUIAR, A.V. Relação entre altitude e temperatura: Uma contribuição ao zoneamento climático no estado do Paraná. R. Estudos Amb., 10:49-64, 2008.

GALVÃO, F.A.D. \& VAHL, L.C. Propriedades químicas dos solos orgânicos do litoral do Rio Grande do Sul e Santa Catarina. R. Bras. Agroci., 2:131-135, 1996.

GAMA-RODRIGUES, E.F.; BARROS, N.F.; GAMARODRIGUES, A.C. \& SANTOS, G.A. Nitrogênio, carbono e atividade da biomassa microbiana do solo em plantações de eucalipto. R. Bras. Ci. Solo, 29:893-901, 2005.

GORHAM, E. Northern peatlands: Role in the carbon cicleand probable responses to climate warming. Ecol. Appl., 1:182$195,1991$.

JEDRYSEK, M.O.; KRAPIEC, M.; SKRZYPEK, G. \& KALUZNY, A. Air-pollution effect and paleotemperature scale versus $\mathrm{d}^{13} \mathrm{C}$ records and tree rings and peat core (Southern Poland). Water, Air Soil Poll., 145:359-375, 2003.

JENKINSON, D.S. \& POWLSON, D.S. The effects of biocidal treatments on metabolism in soil-V.A method for measuring soil biomassa. Soil Biol. Biochem., 8:209-213, 1976.

LANI, J.L. Deltas dos rios Doce e Itapemirim; solos, com ênfase nos tiomórficos, água e impacto ambiental do uso. Viçosa, MG, Universidade Federal de Viçosa, 1998. 169p. (Tese de Doutorado)

LÉVESQUE, M. \& DÍNEL, H. Some morphological and chemical aspects of peats applied to the characterization of Histosols. Soil Sci., 133:324-332, 1982.

MALTBY, E. \& DUGAN, P.J. Wetland ecosystem protection, management and restoration: An international perspective. London, St. Locie Press, 1994.

MARTINEZ-CORTIZAS, A.; PONTEVEDRA-POMBAL, X.; NOVOA-MUNHOZ, J.C. \& GARCIA- RODEJA, E. Four thousand years of atmospheric $\mathrm{Pb}, \mathrm{Cd}$ and $\mathrm{Zn}$ deposition recorded by the ombrotrophic peat bog of Penido Vello Northwestern Espain. Wather, Air Soil Poll., 100:387403, 1997. 
MARTINEZ-CORTIZAS, A.; PONTEVEDRA-POMBAL, X.; GARCIA-RODEJA, E.; NOVOA MUNHOZ, J.C. \& SHOTYK, W. Mercury in a Spanish peat bog: Archive of climate change and atmospheric metal deposition. Science, 284:939-942, 1999.

MCKAY, G. \& PORTER, J.F. Equilibrium parameters of the sorption of cooper, cadmium and zinc ions onto peat. J. Chem. Technol. Biotechnol., 69:309-329, 1997.

MOORE, P.D. The ecology of peat-forming processes: A review. Intern. J. Coal Geol., 12:89-103, 1989.

NELSON, D.W. \& SOMMERS, L.E. Total carbon, organic carbon and organic matter. In: Methods of soil analysis. Chemical methods. Madison, Soil Science Society of America/American Society Agronomy, 1996. Part 3. p.9611009. (Book Series, 5)

PEREIRA, M.G.; ANJOS, L.H.C. \& VALLADARES, G.S. Organossolos: Ocorrência, gênese, classificação, alterações pelo uso agrícola e manejo. In: VIDAL TORRADO, P.; ALLEONI, L.R.F.; COOPER, M.; SILVA, A.P. \& CARDOSO, E.J. Tópicos em ciência do solo. Viçosa, MG, Sociedade Brasileira de Ciência do Solo, 2005. p.233276. v.4.

PONTEVEDRA-POMBAL, X. \& MARTINEZ CORTIZAS, A. Turberas de Galicia: Processos formativos, distribuición y valor medioambiental el caso particular de las "Serras Septentrionais”. Chioglossa, 2:103-21, 2004.

PORTAL BR. Disponível em http://www.br.com.br/portalbr/ calandra.nsf\#http: //www.br.com.br/portalbr/calandra.nsf/ 0/2D5DEA50BF8503FE03256E69004E1150? Open Document \& SDuvidas > Acessado em 27 de fevereiro de 2008.

PRADA-GAMERO, R.M.; VIDAL-TORRADO, P. \& FERREIRA, T.O. Mineralogia e físico-química dos solos de mangue do Rio Iriri no canal de Bertioga (Santos, SP). R. Bras. Ci. Solo, 28:233-243, 2004.

RESENDE, M.; CURI, N.; REZENDE, S.B. \& CORREAA, G.F. Pedologia: Base para distinção de ambientes. 3.ed. Viçosa, MG, NEPUT, 1999. 369p.

SANTOS, R.D.; LEMOS, R.C.; SANTOS, H.G.; KER, J.C. \& ANJOS, L.H.C. Manual de descrição e coleta de solo no campo. 5.ed. Viçosa, MG, Folha de Viçosa, 2005. v.1. 100p.

SHOTYK, W.; NORTON, S.A. \& FARMER, J.G. Summary on peat bog archives of atmospheric metal deposition. Water, Air Soil Poll., 100:213-219, 1997.

SHOTYK, W.; WEISS, D.; APPLEBY, P.G.; CHEBURKIN, A.K.; FREI, R.; GLOOR, M.; KRAMERS, J.D.; REESE, S. \& van der KNAAP, W.O. History of atmospheric lead deposition since $12.730{ }^{14} \mathrm{C}$ yr BP from a peat bog, Jura Mountains, Switzerland. Science, 281:1635-1640, 1998.

SILVA, F.C. Manual de análises químicas de solos, plantas e fertilizantes. Brasília, Empresa Brasileira de Pesquisa Agropecuária, 1999. 370p.

SILVA, A.C. Diagnóstico e avaliação pedológica para o plano de manejo do Parque Estadual do Biribiri. Diamantina, SEMAD/IEF, 2004a. 37p.
SILVA, A.C. Diagnóstico e avaliação pedológica para o plano de manejo do Parque Estadual do Rio Preto. Diamantina, SEMAD/IEF, 2004b. 34p.

SILVA, A.C. Diagnóstico e avaliação pedológica para o plano de manejo do Parque Estadual do Pico do Itambé. Diamantina, SEMAD/IEF, 2004c. 31p.

SILVA, A.C.; VIDAL-TORRADO, P.; MARTINEZ-CORTIZAS, A. \& GARCIA-RODEJA, E. Soils of the São José Hills (Minas Gerais State, Brazil) and their relationship with palaeoclimate in southeastern Brazil. Braz. J. Soil Sci., 28:345-363, 2004d

SILVA, A.C.; PEDREIRA, L.C.V.S.F. \& ALMEIDA ABREU, P.A. Serra do Espinhaço Meridional: Paisagens e ambientes. Belo Horizonte, O Lutador, 2005. 272p.

SILVA, A.C. Diagnóstico e avaliação pedológica para o plano de manejo da Área de Proteção Ambiental Águas Vertentes. Diamantina, SEMAD/IEF, 2005. 53p.

SILVA, E.B.; SILVA, A.C.; FARNEZI, M.M.M.; FERREIRA, C.A.; COSTA, H.A.O.; HORÁK, I. \& GRAZZIOTTI, P.H. Comparação de métodos para estimar acidez potencial através do $\mathrm{pH}$ SMP de Organossolos do Vale do Jequitinhonha, MG. In: CONGRESSO BRASILEIRO DE CIÊNCIA DO SOLO, 31.,Gramado, 2007. Anais. Gramado, 2007. CD-ROM

SILVA, E.B.; SILVA, A.C.; GRAZZIOTTI, P.H.; FARNEZI, M.M M.; FERREIRA, C.A.; COSTA, H.A.O. \& HORAK, I. Comparação de métodos para estimar a acidez potencial mediante determinação do pH SMP em Organossolos da Serra do Espinhaço Meridional. R. Bras. Ci. Solo, 32:20072013, 2008.

SILVA, A.C.; HORÁK, I.; VIDAL-TORRADO, P. MARTINEZ CORTIZAZ, A.; RODRIGUES RACEDO, J; CAMPOS, J.R. Turfeiras da Serra do Espinhaço Meridional. II-Influência da drenagem na composição elementar e substâncias humicas. R. Bras. Ci. Solo, 33:1399-1408, 2009.

SMITH, E.F.; McCARTHY, P.; YU, T.C. \& MARK, H.B. Sulfuric acid treatment of peat for cation exchange. J. Water Poll. Control Feder., 49:633-638, 1977.

STANEK, W. \& SILC, T. Comparisons of four methods for determination of degree of peat humification (decomposition) with emphasis on the von Post method. Canad. J. Soil Sci., 57:109-117, 1977.

UNITED STATES DEPARTMENT OF AGRICULTURE USDA. Soil Survey Staff. Soil taxonomy: A basic system of soil classification for making and interpreting soil surveys. 2.ed. Washington, 1999. (United States Department of Agriculture Handbook, Natural Resources Conservation Service, Number 436)

VALLADARES, G.S. Caracterização de Organossolos, auxílio à sua classificação. Seropédica, Universidade Federal Rural do Rio de Janeiro, 2003. 115p. (Tese de Doutorado)

VALLADARES G.S.; GOMES, E.G.; MELLO, J.C.C.B.S; PEREIRA, M.G.; ANJOS, L.H.C.; EBELING, A.G. \& BENITES, V.M. Análise dos componentes principais e métodos multicritério ordinais no estudo de Organossolos e solos afins. R. Bras. Ci. Solo., 32:285-296, 2008. 